Cad.Est.Ling., Campinas, 47(1) e (2):29-47, 2005

\title{
A CRIANÇA NA LÍNGUA. ERROS DE GÊNERO COMO MARCAS DE SUBJETIVAÇÃO
}

\author{
ROSA ATTIÉ FIGUEIRA \\ (IEL, Universidade Estadual de CAmpinas \\ Grupo de Pesquisa em Aquisição de Linguagem)
}

\begin{abstract}
RÉSUMÉ Cet article a pour but rendre hommage à Claudia Lemos, qui depuis mon doctorat dont elle a été le directeur de recherche, m'a ouvert les chemins que j'ai parcourus pendant 25 ans, dans le Projeto de Aquisição da Linguagem. Il s'agit de présenter sous le titre "l'Enfant dans la Langue" quelques aspects de l'étude du genre. Comme la plupart de nos publications, nous mettons en valeur un découpage méthodologique qui choisit la "faute" et non pas le "correct" comme la donnée de l'élection. Dans cette étude nous analysons un fait particulier de l'acquisition du portugais, par lequel l'enfant réfuse une forme linguistique, en la remplaçant par une autre flexion de genre pour la faire conformer au sexe de l'entité qui est nommée. Notre objet est envisagé en deux axes: sur le plan de la langue (les formes par lesquelles le genre se reálise) et sur le plan du discours (le fonctionnement discursif auquel il se prête). Dans le cas des reprises, il s'agit de répondre à des questions telles que: quand peut-on entrevoir des situations où l'enfant se tourne vers l'énoncé précédent, en produisant une modification qui affecte le genre du mot? Qu'est-ce que cela représente en termes du rapport de l'enfant avec la langue? La description, à partir de la notion d'autonymie (Rey-Debove 1997, AuthierRevuz 1995) fera apparaître un changement de position du sujet (De Lemos 1997). Les données montrent que les petits - âgés de 2 à 5 ans - s'engagent dans un processus de subjectivation, manifesté par des altérations morphologiques non-usuelles, portant sur des mots qui les concernet, soit en tant que filles, soit en tant que garçons.
\end{abstract}

Na perspectiva aberta por esta mesa, cujo título convida a uma retrospectiva do caminho percorrido por cada uma de nós ao longo dos 25 anos do Projeto de Aquisição da Linguagem ${ }^{1}$ - projeto que deve a Claudia Lemos a sua criação e o seu desenvolvimento quero voltar os olhos para os seus primeiros anos, e situar, nos idos de 76, com a chegada da prof. Claudia ao Departamento de Linguística, o início de uma busca incansável por conhecer os mistérios envolvidos no fenômeno da aquisição da linguagem. Esta busca lançou-nos inicialmente, como em vários outros Projetos em outras partes do mundo, a um longo e cuidadoso processo de coleta da produção linguística de uma dezena de crianças entre 1 e 5 anos de idade, pela via da gravação, com a subsequente transcrição do material recolhido.

No nosso cotidiano de pesquisa, ao mesmo tempo em que registrávamos a fala das crianças, sob a forma de gravação ou de Diário, na prática, nossa ansiedade de jovens

${ }^{1}$ Refiro-me ao grupo que se formou em torno da prof ${ }^{a}$ Claudia, constituído por Ester Scarpa, Maria Cecília Perroni, Maria Fausta Castro e eu própria. 
pesquisadoras, em busca da consolidação de um tema para doutorado, conduzia-nos naturalmente a valorizar ou destacar um ou outro fato mais saliente que já despontava na fala dos pequenos, cuja explicação não podia aguardar a finalização da transcrição do material gravado. Foi assim que cada uma de nós dirigiu o seu olhar para um aspecto da fala da criança, envolvidas pela efervescência intelectual que emanava da prof. Claudia. A partir de um pequeno conjunto de dados relacionados à aquisição do léxico ${ }^{2}$, já desenhado como potencialmente interessante, cheguei, em 1977, ao tema que iria render-me uma tese sobre a aquisição dos verbos causativos. Lá estava, num diálogo entre mãe e filha, registrado em Diário, uma fala da criança que considero a "moedinha número 1" de minha coleção, a qual, tendo chamado a minha atenção, mostrei à Claudia, que, por sua vez, me disse: - Há um artigo recém-publicado que trata do mesmo tipo de fenômeno na aquisição do inglês. O dado do português era uma pergunta feita pela criança, ao olhar para a mão da mãe e constatar uma das unhas sem esmalte: Quem saiu o esmalte do dedo, quem? Foi eu? Foi eu? Quem apagou esse esmalte daqui? Quem? (A, 2;11). E a autora do artigo em inglês era Melissa Bowerman, com exemplos semelhantes de Christy: Mommy, can you stay this open? (com dificuldade em sustentar a porta da geladeira aberta; $2 ; 6$ ).

Claudia pôs-me o artigo na mão e daí para frente ficou decidido que eu trataria das relações de causa e efeito no âmbito da sentença (período simples) e a Fausta, que já se inclinava para os porquês, estudaria a relação de causalidade nas estruturas maiores do que a sentença. Para resumir o que seria uma longa história, devo dizer que nossas teses foram defendidas em dezembro de 1985, dois anos depois da tese de nossa colega Maria Cecília Perroni, a primeira do grupo a defender sua tese, que versou sobre a narrativa. A Ester defendeu sua tese na Inglaterra em 1984.

O estudo sobre os verbos causativos marcou de maneira muito forte o meu trabalho, pelo tema em si, que me agradava ${ }^{3}$, e pelo tipo de recorte empírico que a partir dele se instalou, recorte que privilegiou certo tipo de dado, a se consolidar, nos anos seguintes de minha pesquisa, como uma espécie de prática pessoal, de meu contato com os dados: em vez de olhar para o acerto, eu olhava para o que, entre muitas aspas, podia ser chamado "erro".

Na tese trabalhei com dados de uma só criança, longitudinalmente, outra marca dos trabalhos produzidos no interior do Projeto, e este traço ficou expresso no longo nome descritivamente correto - com que minha tese foi intitulada: "Causatividade: um estudo longitudinal de suas principais manifestações no processo de aquisição do português por uma criança ( $2 ; 8$ a 5$)$ ".

A interpretação dos erros envolvendo causativos fez-se através do que chamei de hipótese sintática semanticamente motivada, cabendo sobre "semanticamente", a oportunidade de uma leitura mais ampla, de maneira a incluir as implicações discursivas, indissociáveis, a meu ver, de uma noção de agentividade, em construção na fala da criança.

\footnotetext{
${ }^{2}$ Áreas de Dificuldade na Aquisição do Léxico, publicado nos Anais do II Encontro Nacional de Linguística.

${ }^{3}$ Deu-me a oportunidade de abordar a noção de agentividade em conexão com as nuances de causação, resultando em artigo de 1986: "Agente e Culpado: papéis que se recobrem nas construções causativas com fazer'.
} 
Cadernos de Estudos Lingüísticos 47(1) e (2) - Jan./Dez. 2005

O trabalho despertou o interesse de alguns pesquisadores. No Brasil houve da parte de Whitaker-Franchi uma disposição em reanalisar os dados num outro quadro teórico (gerativo, hipótese maturacionista). E fora do Brasil, graças a uma publicação no Journal of Child Language (1984), o trabalho recebeu, dois anos depois dentro da mesma revista, num artigo escrito por Hochberg ("Children's Judgements of Transitivity Errors", 1986), um espaço de discussão. Na resenha que a autora faz dos trabalhos existentes sobre erros de transitividade, a hipótese para os erros de causatividade na aquisição do português é apresentada ao lado de outras, como a de Bowerman (1974, 1982), a de Lord (1979) e Berman (1982), para dados análogos relativos à aquisição do inglês e do hebraico.

Hoje vejo com satisfação que o conjunto de dados sobre causativos que coletei representa um fenômeno a que outros pesquisadores, observando crianças aprendendo a falar outras línguas, também foram sensíveis. O ângulo sob o qual abordá-lo poderá (como de fato acontece...) variar de acordo com a posição teórica do autor, mas o dado, este parece estar sempre disponível, a unir um certo número de estudiosos em torno dos "corpora", e a provocar, a cada vez, novas e mais ricas discussões.

Como consequência natural do tipo de análise desenvolvida na tese, meu foco foi se fixar no tema "processos reorganizacionais", para a exploração do qual formulei, em 1991, um novo projeto de pesquisa. Abordar fatos estruturais (morfológicos, sintáticos e lexicais) da mudança linguística operada na fala da criança, passou a ser o meu alvo. Ampliei a observação, de modo a acolher os dados de mais um sujeito $(\mathrm{J})$, e projetei algumas classes de dados, em relação às quais teria a oportunidade de reconhecer a mudança sob a forma de "erros", inovações ou, se melhor, formas divergentes - como sugeri chamá-los, já incomodada pela impropriedade da palavra erro. A primeira foi a classe semântica dos verbos que expressam reversão de processo ("reversal actions" ou "undoing actions", como é conhecida na literatura). A segunda, a classe dos deverbais regressivos e de outras inovações lexicais, presentes no vocabulário entre os 3 e 5 anos de idade. Por fim, e isto era inevitável quando se tematiza o "erro", uma atenção para o verbo e sua face flexional. Domínio de uma certa fartura de erros, porque não há quem não tenha se detido nos fazi e nos sabo, registrados em algum ponto da produção linguística da criança. Mas, a verdade é que não estava interessada exclusivamente nesse tipo de erro que afeta os irregulares, fenômeno sempre associado na literatura à discussão da "overextension”. Queria mostrar a existência de uma outra classe de erros, muito mais interessante, porque afeta os verbos ditos regulares. Menos lembrados ou explorados, mas igualmente importantes, estes resultam numa parcela significativa dos dados sobre a aquisição da morfologia verbal do português, sem paralelo no inglês, a língua cuja aquisição tem sido mais ampla e detidamente estudada.

Minha disposição em estudar esta constelação de dados ficou expressa num texto escrito em 1991 para participar da II ENAL, em Porto Alegre, e hoje tem a forma de um artigo, intitulado "O Erro como Dado de Eleição nos Estudos de Aquisição da Linguagem”4 . Este artigo desempenhou, na minha modesta produção, um duplo papel: serviu para situar

${ }^{4}$ Publicado em 1996, em O Método e o Dado no Estudo da Linguagem, tendo M. Fausta Castro como organizadora. 
e defender a relevância teórica e metodológica do erro em nossa área de investigação, e funcionou também como uma espécie de plano de trabalho, público e explícito, para os estudos que se desenvolveram entre 1992 a 1997, cujo resultado foram os artigos: "A Aquisição dos Verbos Prefixados por des-"5 "Erro e Enigma na Aquisição da Linguagem", "A Palavra Divergente. Previsibilidade e Imprevisibilidade nas Criações Lexicais da Fala de Duas Crianças" e "L'Acquisition du Paradigme Verbal du Portugais Les Multiples Directions des Fautes".

$\mathrm{Na}$ interpretação do chamado "erro", o percurso feito parte de uma visão de reorganização, compatível com modelos construtivistas (Bowerman 1982), para uma visão de ressignificação, da hipótese interacionista de Claudia Lemos (1992). Minha adesão a esta última passa por uma consideração da heterogeneidade linguística, característica a que o "erro" confere visibilidade, na medida em que exibe uma possibilidade distinta daquela que já está cristalizada na língua adulta. Assim é que, ainda na esteira do erro como dado de eleição, coube-me por último assinalar o caráter imprevisível do erro, sua contingência e singularidade, num dos domínios gramaticais mais visitados em qualquer estudo que escolha o erro como tema: a aquisição da morfologia verbal. Por isto, vou me permitir, nesta apresentação, deter-me um pouco mais neste domínio, retomando passagens do artigo por último mencionado.

Entre 2 e 5 anos, há um número apreciável de formas verbais divergentes, que apontam para uma falta de correspondência do morfema flexional relativamente à classe de conjugação a que o item pertence. Eu tô dirijando, Eu vô dirijá, Eu escrevei, Eu aprendei, Eu caiei, A Anamaria não pode atendá (o telefone). Só o papai pode atendá, Tá ardindo aqui no meu pescoço, Eu não escondava, Quanto tempo eu não ouçava essa música, Eu experimenti e gostei, Eu já escovi (os dente), Antes ela não fechia, Cê passia talco em mim? são enunciados que podem ser ouvidos com certa frequência na fala das crianças. Tal como em pesquisas anteriores, este aspecto da constituição da gramática (recolhido da produção linguística de A e J) interessou-me pelo ângulo daquilo que os erros, que ocorrem antes da estabilidade final, podiam revelar.

Uma constatação inicial guiou-me para bem longe de uma hipótese de aquisição instantânea: erros são observados depois e também ao lado de formas aparentemente corretas. Tal fato leva a colocar em dúvida que a organização desta parte da gramática venha a passar pelo reconhecimento prévio (um lugar no dicionário mental) da forma abstrata do verbo - sua forma infinitiva - à qual a criança aprenderia a associar, instantaneamente e de uma vez por todas, a desinência adequada, de acordo com a terminação dessa forma remeter a -ar, -er ou -ir. Se assim o fosse, a criança acertaria desde o início e nunca erraria. Como tal não acontece, prevalece a proposição, presente nos modelos

\footnotetext{
${ }^{5}$ Encerrado em agosto de 1994, foi publicado em 1999, na revista PaLavra.

${ }^{6}$ Escrito em novembro de 1994, para o III ENAL em Porto Alegre, foi publicado nos Anais do Congresso, em 1996.

${ }^{7}$ Apresentado na XI ALFAL e publicado nos Trabalhos em Linguística Aplicada.

${ }^{8}$ Publicado na revista CALAP, sua versão para o português integra o volume Saudades da Língua (2003), do qual as passagens acima foram extraídas.
} 
Cadernos de Estudos Lingüísticos 47(1) e (2) - Jan./Dez. 2005

construtivista e interacionista, de que o material inicial é não-analisado e só depois submetido a processos de reestruturação (ditos aqui e ali de "redescrição", "reorganização" ou "ressignificação"), processos esses identificáveis pelo erro.

A pergunta feita a seguir foi: há uma forma básica que atua na organização desse domínio? (A candidata seria as flexões de 1. ${ }^{a}$ conjugação, já que é a mais frequente e numerosa na língua, e também a mais produtiva, por onde dão entrada formações neológicas). A resposta exigiu que percorresse toda a evidência empírica disponível, isto é, que "varresse" os dados de A e J. O resultado foi o levantamento de cerca de 87 ocorrências flexionalmente destoantes. Resumindo os meus achados, pode-se dizer que os dados exibem uma certa recorrência: há, para um dos sujeitos (mas não para o outro) o que chamei de alinhamento inicial de formas verbais pelo padrão de $1 .^{\text {a }}$ conjugação, a que se segue um alinhamento de formas pelo padrão de 2. (e/ou 3.a) conjugação, mas tal movimento está longe de ser absoluto, total, como se derivasse da aplicação cega e irrestrita de uma regra, a atingir igualmente todos os seus alvos ou todos os alvos suscetíveis de concordar com ela, num efeito de padronização, assimilável à representação de um cálculo. Coexistem, em cada um dos períodos observados, erros que apontam para um outro ponto de cruzamento, destoante daquele supostamente comandado por uma regra de aplicação absoluta. Para dar conta desses, fomos obrigados a admitir uma dominância apenas relativa dos morfemas de uma classe de conjugação, afastando-se a possibilidade de explicar a constituição do paradigma verbal por substituição de regra ("rule replacement"), uma hipótese de pé na literatura geral da área, para explicação para a aquisição de domínios fortemente afetados pela alomorfia. Aquilo que os dados nos mostraram foi - para introduzir uma expressão usada na análise - um mosaico de formas deslocadas de seu lugar, um quebra-cabeça com raízes verbais seguidas de terminações que não se compatibilizam com a sua classe de conjugação, onde, rigorosamente falando, não há movimento univocizante, correspondente à dominância absoluta de marcas de uma só conjugação.

Bom, a literatura sobre processos de reorganização já tinha nos ensinado a olhar para esses dados como indícios de uma sistematização em curso. Mas, conforme mostrado, nenhum modelo, que elejesse a curva-em-U como a melhor representação da mudança expressa na sequência "acerto-erro-acerto", parecia apto a abrigar os dados na forma como encontrados. A curva em U é uma idealização que faz supor que a classe dos objetos linguísticos afetados por uma regra o seja de maneira completa e identicamente previsível.

Num diálogo com o modelo de Karmiloff-Smith (1986), procurei verificar como seria a descrição dos dados dentro dessa proposta. Sem passar aqui pelas etapas da argumentação, vou direto à conclusão. A constatação de que "erros" convivem com acertos, e, que não se pode prever quais objetos linguísticos serão, a cada momento afetados pelos cruzamentos de morfemas de outras classes de conjugação (e isto não só no domínio de observação de um mesmo sujeito, como no que procura comparar sujeitos diferentes em sua trajetória de aquisição), torna difícil explicar tais dados dentro de um modelo que procura traçar uma ordem ou níveis de organização/representação sucessivos, mesmo que se admita que movimentos de ida e vinda aí possam ter lugar. $\mathrm{O}$ fato de que não se pode prever quais os itens que poderão ser, em cada caso, por cada sujeito, afetados por esse processo coloca o investigador diante do desafio de explicar a imprevisibilidade, fenômeno 
que, a meu ver, deve ser enfrentado como uma característica própria de acontecimentos linguísticos, muitas vezes singulares e únicos, de cada sujeito em cada momento de sua relação com a língua(gem), e como tais merecedores de tanta atenção quanto aqueles que apontam para a situação oposta (a regularização, a previsibilidade).

Ora, tal como procurei mostrar, uma proposta que faz frente a esse desafio é a enunciada por Claudia Lemos (1992), porque abre a perspectiva de se colocar como determinante da mudança linguística operada na fala da criança as relações entre objetos linguísticos de qualquer extensão (um morfema, uma palavra, uma sentença...), graças a um processo de ressignificação, que opera no eixo metafórico ou metonímico, os eixos de funcionamento da linguagem. Permite contemplar aquelas ocorrências afetadas por cruzamentos imprevisíveis, resultantes de relações entre material presente ou apenas evocado na cadeia dos enunciados. Por exemplo, episódios como: Ai, nem me diga! A senhora nem vai me digar; "Agora eu entendi". Então ela entendiu mãe ; Se a Ju batia a lata bem forte, cortia a cara?, para os quais é impossível ignorar que o produto (o erro) permaneça alheio ou a margem da relação com a fala adjacente. Ele deriva de uma relação contingente com o material linguístico ali presente, contribuindo para contra-argumentar à posição de que os agrupamentos sistêmicos se estruturem via processo endógeno, à margem da experiência da criança com a linguagem - como quer Karmiloff-Smith (1986).

Ao abordar essa última classe de dados acreditava eu ter concluído aquilo que tinha me proposto como tarefa em 1991, e já me dava por satisfeita em relação ao tema "erro". Novas questões surgiam em meu horizonte de pesquisa, ao ensejo da "descoberta" de cinco adivinhas criadas por $\mathrm{J}$ e dirigidas ao adulto, à guisa de entretenimento. Como em outras ocasiões, mostrei o meu achado à Claudia, que me estimulou para a análise deste novo e original material. Preparava-me assim para fixar-me num outro universo empírico, aquele que se precipita sobre um corpo de dados que na literatura costuma ser rotulado como habilidades metalinguísticas: as correções da criança sobre a fala do outro, as autocorreções, as reformulações, as primeiras definições e os jogos verbais. O material empírico que se descortinava era abundante e convidava-me a uma exploração via aporte teórico, novamente trazido por Claudia Lemos, na formulação das chamadas três posições da criança (1997). Mostrava-se apto a integrar uma pesquisa visando descrever "As Primeiras Manifestações da Propriedade Reflexiva da Linguagem na Fala da Criança" .

Nesta altura, surgiu a necessidade de contar com uma noção que conferisse unidade descritiva ao conjunto de dados. Fui encontrá-la na noção de autonímia, ampla e detidamente estudada por Rey-Debove (1978/1997) e redimensionada por Jacqueline Authier-Revuz (1995). A pesquisa avançava assim para as situações em que a criança se volta para o que disse ou para o que o outro disse, fazendo destacamentos autonímicos, uma condição compatível com o que Claudia Lemos vinha chamando de terceira posição: um deslocamento que torna a criança capaz de reconhecer a diferença entre a sua fala e a de seu interlocutor.

${ }^{9}$ Tal foi o título do projeto apoiado pelo CNPq, sub-intitulado: "o que revelam sobre a relação da criança com a língua". Um dos resultados foi o artigo "Children's Riddles: what do they tell us about change in language acquisition?", exposto em 1996 no 5th International Pragmatics Conference, publicado em 1997, nos Cadernos de Estudos Linguísticos. 
De frente para dados muito variados, procurei mostrar que em tais situações é possível identificar não só uma retomada autonímica da palavra ou expressão (destacada da própria fala ou da fala do interlocutor), mas também, em alguns casos, o que chamei de saisie autonymique $^{10}$. Há episódios em que é nítida a tentativa da criança de fazer graça ou brincar, seja através de jogos verbais (como as adivinhas), seja através de brincadeiras com o nome próprio, algumas delas assumindo a aparência de trocadilho, tal como no seguinte exemplo de A: depois de ouvir o nome Dagmar três vezes, A, entre curiosa e brincalhona, dispara: Dagmar? Não é Dagchão?.

É bom recordar que na literatura geral da área o estudo das chamadas habilidades metalinguísticas se faz predominantemente pela via de estudos experimentais, procurando fixar a idade aproximada em que as crianças são capazes de compreender e apreciar jogos que assentam sobre propriedades linguísticas. (Assume-se que são tardias, aguardadas num ponto mais avançado do processo de aquisição da linguagem, aos 6, 8 anos de idade (Clark (1978), Kess (1990) e Hakes (1980)). Diferentemente, na pesquisa que procurei implementar, adotou-se outro enfoque metodológico, com o registro longitudinal de pelo menos dois sujeitos (A e J; fonte: Diário e gravações; 2 aos 7 anos de idade), mas tendo também outros à disposição, na direção de reunir as manifestações mais precoces da propriedade reflexiva da linguagem na fala da criança. Não foi difícil ver que tais acontecimentos não são destacados do uso ordinário da linguagem, nem podem ser presumidos com temporalmente ordenados, como aparece na maioria das propostas desenvolvimentistas (Hakes 1980, por ex). Tal como pude constatar, algumas das chamadas habilidades metalinguísticas surgem anos antes da chamada "maturidade linguística" (idealmente fixada em torno dos 5), a explicação de novo me remetendo às formulações teóricas do interacionismo, que recusa uma visão de estágios (De Lemos 1996, 1997).

Ao ingressar nesse novo domínio empírico parecia que tinha me afastado do tema "erro", que por muito tempo alimentara minha pesquisa. Mas eis que, ao estudar as retomadas, fui de novo cair no velho tema. E, desta vez, no erro que incide sobre as marcas de gênero, num tipo de enunciado que tem uma particularidade interessante: vem acompanhado de um efeito anedótico, engraçado. A pesquisa subsequente foi dirigida então para a chamada "marcação insólita de gênero". Retomando o diálogo com Jacqueline Authier-Revuz sobre a presença do fato autonímico na fala da criança ${ }^{11}$, selecionei a classe das réplicas contendo marcação divergente de gênero, como um terreno propício para discutir a presença da criança na língua, o que levou-me a intitular a versão final deste trabalho "L'Enfant dans la Langue" 12 , numa homenagem a Benveniste. Com efeito, os

${ }^{10}$ Relatório do estágio de pós-doutorado (2002) e Figueira 2004 (no prelo).

${ }^{11}$ Diálogo iniciado em 2000, a propósito de uma comunicação sobre humor e aquisição da linguagem, onde já figuravam algumas ocorrências contendo marcas insólitas de gênero. Adiante, aparelhada pela noção de autonímia como ferramenta descritiva, a pesquisa ampliou-se, dando lugar ao artigo: "La Propriété Réflexive du Langage dans le Parler de L'Enfant. Quelques Aspects Pragmatiques et Discursifs". Um pouco depois, em 2002, o estágio de pós-doutorado na França, a convite da prof. Jacqueline Authier-Revuz, apoiado pela FAPESP, abriu novos caminhos à investigação. 
achados apontam não só para um momento da construção de um subsistema gramatical (as marcas formais de masculino e feminino), mas para a constituição da criança como falante e como identidade no mundo. É a um trecho desta análise que vou destinar a parte final desta minha fala, não sem antes dizer que, inscrevendo-se ainda numa reflexão sobre o erro, este estudo acabou por se revestir, do ponto de vista metodológico, de um interesse pela discussão sobre o papel do dado anedótico nas pesquisas da área. Convencida de seu inegável poder heurístico na análise de alguns subsistemas gramaticais, como o do gênero, dispus-me a uma reavaliação desta fonte, fonte que remonta à tradição dos diaristas ${ }^{13}$.

Focalizando as marcas de gênero na fala da criança, minha atenção voltou-se inicialmente para algumas afirmações existentes na literatura. Alguns estudiosos investem na hipótese de que é a sua expressão sintática (ou morfossintática) o fator relevante neste processo (Correa 2001). Suposição corroborada pela evidência empírica disponível: o mecanismo sintático da concordância, particularmente a concordância no interior do sintagma nominal, no caso do português, está apto a exibir a atribuição do gênero gramatical ${ }^{14}$, em ocorrências chamadas "corretas". Mas na medida em que o acerto convive com o "erro", foi a este último que decidi voltar a minha atenção, focalizando aquelas ocorrências em que, falando de si (menino ou menina, ela ou ele), a fala da criança faz aparecer alterações no sintagma e/ou no próprio corpo da palavra. São alterações que se revelam cruciais para lançar luz sobre um dos fenômenos mais instigantes desse objeto: a identificação entre categoria gramatical e expressão de $\operatorname{sexo}^{15}$. Com efeito, os enunciados infantis parecem reacender a velha discussão sobre a motivação semântica do gênero, discussão que, como afirmam Arrivé e alii (1986:284), estimula de tempos em tempos o debate.

Uma vez definido o recorte empírico, a análise pautou-se em dois eixos: no plano da língua, as formas pelas quais o gênero se realiza, e no plano do discurso, o funcionamento discursivo a que se prestam. (A partir deste ponto retomam-se, com pequenas alterações, passagens do artigo "Marcas Insólitas na Aquisição do Gênero. Evidência do Fato Autonímico na Língua e no Discurso"16).

Começo por mostrar um tipo de erro de gênero, relativamente comum na aquisição do português, aquele que incide sobre substantivos que, por escaparem ao padrão geral da língua ( terminação -o para masculino, -a para feminino) acabam, na fala da criança, por se alinhar ao padrão mais consistente. São exemplos: um tapo ou a tapa para um tapa ou $o$

${ }^{12}$ Relatório do estágio de pós-doutorado, enviado à FAPESP.

${ }^{13} \mathrm{Tal}$ interesse fez nascer o tema do projeto de pesquisa atual (CNPq, 301478/2003-5): "Revisitando a Contribuição dos Diaristas".

${ }^{14}$ Ver, por exemplo, a discussão sobre o gênero levada por Mattoso Câmara Jr. (1970, 1972, 1975), da qual se faz um apanhado em Figueira 2001b.

${ }^{15}$ Como os dados a serem analisados adiante relevam tanto da marca morfológica não-motivada quanto da marca semanticamente motivada, conservamos o termo gênero para o conjunto dos dados em discussão. Uma expressão composta - gênero-sexo - será introduzida quando a questão do sexo nos parecer implicada no uso feito pela criança da palavra alterada quanto ao gênero.

${ }^{16}$ Exposto em 2002 (XIII ALFAL), publicado com data de 2001. 
Cadernos de Estudos Lingüísticos 47(1) e (2) - Jan./Dez. 2005

tapa; um amoto ou o amoto por uma moto ou a moto: Deu um tapo na cara, Gostou da $\underline{\text { tapa }}$ ? , O papai tá aqui porque o amoto dele tá aqui. Ampliando-se a observação para a classe dos adjetivos temos:

(1) (a cr. fica sensibilizada depois de ouvir a mãe contar algo sobre criança desprotegida)
A. Ela é pobra. Ela é pobra, mãe?
$(5 ; 3.17)$

(2) (depois de ouvir os pais conversarem sobre queda de cabelo $J$ (aborrecida). Ah, eu não gosto de pai careco.

(3) (A e J brincam de repórter, a primeira fala sobre o prédio em construção ao lado de sua casa). J.. Tá 'petando (= está apertando) muito a minha casa com aquele prédio idioto. ( 4;5.25)

Pobre, idiota ou careca, adjetivos apostos, respectivamente a: (criança), prédio e pai, viram pobra, idioto e careco, conformando-se ao gênero dos substantivos aos quais estão sintaticamente relacionados: feminino (criança pobra) ou masculino (prédio idioto, pai careco). Constata-se que a classe dos adjetivos chamados na literatura de uniformes uma forma única para o masculino e o feminino - é tratada como a classe dos biformes, mais uma evidência de que a aquisição desse subsistema pela criança passa por um movimento de ultra-regularização, que recai sobre objetos linguísticos, de maneira a uniformizar seu comportamento, afetando o modo de funcionamento dessa categoria na língua da criança, em comparação com a língua do adulto ${ }^{17}$. O resultado disso é o que um observador chamaria de "erro de gênero", fenômeno que, de resto, já tinha sido mostrado no artigo "O Erro como Dado de Eleição". A novidade que a pesquisa atual acrescentou à análise de tais dados reside - é preciso pôr em destaque - na constatação de que, nas falas acima, o nome está sendo simplesmente usado. Trata-se do signe mondain (signo mundano), para falar como Rey-Debove (1997:22), que toma o termo emprestado a Barthes. É o signo remetendo a uma entidade do mundo e não a si mesmo como signo. Ora, uma coisa completamente diferente acontece nas ocorrências reunidas em outro conjunto, onde o que temos são exemplos de retomadas autonímicas.

Do ponto de vista linguístico-discursivo tais retomadas foram classificadas em retificações e réplicas, termos que usei à falta de outros melhores. Retificação quando a retomada da criança incide sobre um ponto da própria fala; réplica quando a criança apõe à fala do outro uma outra forma que lhe é divergente, ou até, controversa. Nos dois casos um substantivo é alvo, na sua desinência, de uma outra marca de gênero. Se na ocorrência anterior era masculino torna-se feminino, e vice-versa ${ }^{18}$. Veja-se a ocorrência (4), um caso de retificação.

${ }^{17}$ Exemplificamos com o SN complexo, mas não são desconhecidas marcas insólitas de gênero no SV. Veja-se o caso de: A Fávia é nananda (De Lemos 1992:130), na qual a concordância se espalha para a forma do gerúndio, produzindo nananda, item que passa a funcionar à maneira de um adjetivo (ex: bonito/bonita), na posição de predicativo do sujeito. Exemplos semelhantes, encontrados no corpus de J, não serão mostrados aqui por limitação de espaço. 
(4) (J toma seu café da manhã; a certa altura pergunta a sua mãe)

$J$. Carro bebe café, mãe?

M. Não.

J. Então eu não bebo. Porque eu sou carro.

M. ?!

J. Quer dizer, eu sou carra. Sou carrinha. (D-4;6.28)

Neste episódio a expressão quer dizer serve para introduzir um reparo que afeta não apenas a coisa que foi dita, mas a palavra, na forma como esta coisa foi dita. Na medida em que exibe um fato morfológico não-usual, este dado tem um ar divertido, engraçado: a criança flexiona o substantivo carro, dizendo carra, para fazê-lo conformar-se à expressão de um ser do sexo feminino (ela, Juliana), e em seguida, ainda falando si (uma menina), busca uma adequação semântica correlata: carra torna-se carrinha. Gênero feminino, no diminutivo.

Da mesma faixa de idade, eis outra ocorrência de $\mathbf{J}$.

(5) (J brinca de fazer entrevistas, como se fosse o repórter na televisão)

$M$. Eu tava perguntando se ia sair ou não a reportagem, Ju. E você é o repórter.

$J$ (levantando a voz). Reporta.

M (rindo). "Reporta"? Por que "reporta"?

J. Por que reporta é mulher. Que eu não quero ser homem. Eu sou reporta, vai. $\quad$ (D-4;6.1)

Neste caso J marca o gênero numa palavra onde ele (o gênero) não teria marca formal explícita no vocábulo. Falando tecnicamente, réporter é um desses substantivos que Mattoso Câmara classificaria como de dois gêneros sem flexão. Neles o gênero torna-se conhecido pela forma masculina ou feminina do artigo que implicitamente exigem (o repórter /a repórter; tal como o artista /a artista, o mártir /a mártir). Aliás, este fato - como lembra o linguista brasileiro, citando a Vendryès - "torna-se de um mecanismo preciso e nítido em línguas que, como o grego e o português, têm a partícula chamada "artigo", sempre implicitamente possível de se antepor a um nome substantivo" (Mattoso Câmara 1970:81).

Ora, o que se observa na fala de J? Uma marca formal, no corpo da palavra, na terminação -a (reporta). É aí que a criança inscreve - de maneira inequívoca a qualquer interpretação - a sua inegociável condição de menina, portanto sexo feminino, portanto gênero feminino. Mais ainda, neste caso, como se pode ver, a criança dá uma explicação da marca de gênero: "Porque reporta é mulher. Que eu não quero ser homem. Eu sou reporta, vai."

Antes de passar às réplicas, transcrevo uma ocorrência particularmente interessante, que foi extraída do Diário de A, e que tem J como interlocutora. Frente a frente as duas irmãs: $\mathrm{A}$, de 8 anos e $\mathrm{J}$ de 5 anos.

${ }^{18}$ Um exemplo dessa segunda possibilidade é encontrado no episódio (10), registro que me foi oferecido por Claudia Lemos. 
Cadernos de Estudos Lingüísticos 47(1) e (2) - Jan./Dez. 2005

(6) (A e J, as duas irmãs, ouvem um programa de auditório na tevê; a certa altura o apresentador dirige-se ao auditório com a saudação: Bom dia!)

A (a mais velha). Bom dio!

(J, a mais nova, faz uma intervenção, "corrigindo" a irmã)

J. Bom dio é para homem. Bom dia é para mulher.

$(D-5 ; 2.17)$

Concentrêmo-nos inicialmente no que diz A. Ela responde ao cumprimento, fazendo uma alteração na palavra dia, que é produzida dio. Aparentemente para se conformar a uma regularidade da língua: a maioria das palavras que se deixam antepor por adjetivos como bom, são terminadas em -o . Dia, palavra masculina, faz exceção, porque termina em -a. De alguma maneira, nesta ocorrência, esta "discrepância" do sistema é eliminada, promovendo-se uma solidariedade entre os significantes bom e dio (note-se que ocorrências como uma tapa e um amoto exigiram o mesmo tipo de consideração).

Mas o mais curioso é o que se segue na resposta da menina mais nova. De modo sério e sentencioso ela dispara uma regra de uso do cumprimento, regra na qual novamente a marca formal que se alterna no final do substantivo parece servir para marcar dois universos: o das mulheres e o dos homens. Partindo da mesma criança que sentencia em (5): Porque reporta é mulher, a enunciação Bom dio é para homem. Bom dia é para mulher obriga a algumas outras explorações. Note-se que a criança não parece fazê-lo na direção de provocar o riso, ela produz seu enunciado de maneira "sincera", indiferente ao efeito insólito, até divertido de suas palavras. Confrontados com uma enunciação como a de J em (6), é difícil não exclamar: eis aí um discurso da criança sobre a língua! Discurso que, ademais, revela para o observador o caminho que o funcionamento do gênero gramatical asssumiu na estória da aquisição da língua materna por essa criança.

Instrumentalizados com a noção de autonímia, procurei mostrar que há fato autonímico, numa estrutura de "boucle" (para tomar aqui emprestado o termo de Authier-Revuz), seja ela auto-iniciada, quando a criança retoma o seu dizer, como em (4), seja ela hetero-iniciada, quando é desencadeada pelo dizer do adulto, como em (5). Quanto às marcas formais da autonímia, observam-se acima alguns índices, como por exemplo, a ausência do determinante, um sinal importante de que o signo está sendo mencionado e não apenas usado (Rey-Debove 1997: 64-65).

No estudo sobre o gênero um lugar importante foi reservado às chamadas réplicas. Trata-se de uma classe específica de enunciados que exibe (ou pode potencialmente exibir) uma característica formal, estrutural. O enunciado começa por uma negação, e é seguido por duas estruturas de predicação: Não, não é $X$, é $Y$, onde $\mathrm{X}$ e $\mathrm{Y}$ são signos autônimos, palavras tomadas em menção e não como signos ordinários. Do ponto de vista da enunciação há uma recusa, pela qual a criança descarta não a coisa que é nomeada (o referente), mas a palavra pela qual esta coisa é nomeada pelo interlocutor, um adulto. Oferece então uma outra palavra, que lhe parece a correta. Um caso de não-coincidência do dizer, para utilizar livremente a expressão - título do livro de Authier-Revuz (op.cit.). Vejam-se os exemplos de J, entre $2 ; 3$ e $3 ; 3$.

(7) ( $J$ dá uma batida no braço; forma um galo; a mãe mostra à avó, dizendo)

M. Fez um galo.

J. Não é "galo", é "galinha".

$(D-3 ; 3)$ 
FIGUEIRA - A criança na língua. Erros de

(8) (a mãe de J tenta pôr um biquini que não lhe serve; J segue o que faz a mãe)

$J$ (avaliando). Esse não dá mãe.

M. Ah Ju! Você é um barato.

J. "Barata", mãe, "barata".

$$
(D-2 ; 3)
$$

Diante de tais falas interroguei-me: - Por que J substitui barato por barata e galo por galinha? Não foi difícil ver que se trata da marcação de sexo atravessando os itens que a qualificam ou que fazem referência a algo que afeta a ela, Juliana, uma menina. Em favor desse movimento falam os episódios (4), (5) e (6), expostos em primeiro lugar e que servem para dar apoio à idéia. Eles chamam a atenção para a questão: em que medida uma categoria gramatical acaba por ser investida de aspectos que relevam da identidade do locutor?

Isto me fez analisar cada dado separadamente. Em (8), a réplica de $\mathrm{J}$ a sua mãe Barata, mãe, barata deixa implícito que a criança, a quem escapa o sentido da expressão idiomática um barato (aproximadamente: você é impagável), acaba por lhe imprimir um outro sentido. Qual ? - foi a pergunta que me fiz. Qualquer que seja ele (não sabemos...), deve obrigatoriamente tratar-se de uma predicação de menina, uma vez que J lhe imprime a marca de feminino: barata, e ela o faz indiferente ao fato de que erige-se com isto uma situação de homonímia. (Barata corre o risco de ser interpretada com outro sentido: aquele que se refere ao inseto, mas certamente não é disto que a criança está falando...). Estamos de novo diante de uma situação em que J imprime no enunciado sua inescapável condição de menina, condição à qual ela se agarra, fazendo-a presente formalmente na língua. A estrutura completa seria: (Não é barato), é barata - se procurarmos desdobrar seu enunciado, de modo a reconstituir a estrutura da réplica.

Já em (7), encontramos a estrutura completa Não é X, é Y. J retoma a palavra galo para recusá-la ( Não é galo ) e colocar em seu lugar galinha. Encontram-se aí, na fala de uma garotinha que não tem mais do que 3;3 de idade, todos os elementos da fórmula estrutural da réplica, um fraseado linguístico que é posto a serviço da necessária identificação de J como ser do sexo feminino. Mas será que, uma vez feito o reparo ou a reformulação, chega a criança a dar-se conta do inesperado efeito anedótico de suas palavras? Aparentemente não. Mas a nós, adultos, que escutamos a fala da criança, não passa desapercebido o efeito engraçado dessas intervenções. Por isto mesmo, tais dados não cessam de suscitar outras questões, as quais têm me conduzido a alinhavar algumas idéias sobre o efeito da fala da criança sobre o interlocutor adulto, efeito que nos põe de frente para o tema do humor na aquisição da linguagem (Figueira 2001a). Neste contexto entrevi a pertinência de uma noção que procuro definir como saisie autonymique: a enunciação da criança desencadeia no interlocutor uma reação na qual o fenômeno da autonímia está também implicado. Com efeito, para que o receptor se dê conta do aspecto insólito da fala da criança, é preciso que ele depreenda o outro sentido que circula na réplica da criança. Nesse momento ele experimenta - tal como em Dagmar/Dagchão ou em (7) - a sensação de descobrir os sentidos alternativos que percorrem a materialidade da língua, portanto a ocasião de colocar em jogo o signo, no seu estatuto autonímico ${ }^{19}$.

${ }^{19}$ Este aspecto está, de resto, envolvido em muitos jogos verbais, como por exemplo nas adivinhas que jogam com segmentações divergentes. 
Cadernos de Estudos Lingüísticos 47(1) e (2) - Jan./Dez. 2005

É útil retomar o episódio (7), para explorá-lo nessa direção. Primeiramente ocorre na fala de M o item galo, cujo significado é "pequena inchação resultante de pancada". Na réplica de J fica evidente uma relação insólita: o significante galo ganha uma marca de gênero, e, isto acontece - tanto quanto se pode supor - para se conformar à entidade a qual se aplica (um machucado num ser do sexo feminino). Não se pode ter certeza de quais fatos se cruzaram nesta estranha ocorrência, mas o mínimo que se pode imaginar é que o significante galo (associável na língua adulta a dois significados distintos e independentes - um caso portanto de homonímia), comporta naquele emprego, para a criança, um significado que exige a marca gramatical de gênero. Um ponto interessante a ser assinalado é a indiferença da criança ao efeito criado junto a seu interlocutor por esta substituição: galinha corre o risco de ser interpretado como a fêmea do galo (o animal) e não como o machucado de que é portadora uma menina... Assim, o enunciado, dirigido em tom firme e assertivo, à guisa de correção: "Não é galo, é galinha" é potencialmente capaz de fazer rir, mas não parece ter sido produzido com este objetivo; e, para o investigador só poderá ser encarado como um dado-indício de uma relação específica da criança com a língua, relação pela qual a criança faz a língua curvar-se ou dobrar-se à marca de sua inegociável condição de menina. Seja permitido dizer que, chegando-se a este ponto, é possível recuperar em toda a sua evidência a etimologia da palavra flexão: "do lat. flexione, ação de dobrar"20. Seja permitido também acrescentar que, ao inventar (ou reinventar?) palavras como galinha, no lugar de galo (= elevação consequente à pancada), a criança encontra, junto a procedimentos que a própria língua lhe oferece, um meio de fazer aparecer aquilo que nesta língua poderia ser um lugar de ocultação de sua identidade sexual ${ }^{21}$. Neste ponto, diante do insólito das "correções" de J, é livremente que retomo uma afirmação de Claudia Lemos para assinalar que "tais correções não ocorrem sempre onde se faria necessário e podem ocorrer quando não parecem necessário, não sendo, portanto, previsíveis (...)"’22.

Fazendo um balanço dos dados apresentados, de (1)-(3) a (4)-(8), proponho agora analisá-los do ponto de vista enunciativo. Nos primeiros (em que o signo é apenas usado) temos asserções e perguntas; nos segundos (em que o signo é mencionado) temos enunciações do tipo replicante, que retomam o enunciado anterior do interlocutor, corrigindo-o; ou então do tipo retificador, que retomam o próprio enunciado. Esta particularidade que, sem dúvida, diz respeito ao discurso - discurso sobre a língua - instaura uma não-coincidência ou uma discordância entre os interlocutores ${ }^{23}$, discordância cuja sede e cujo objeto é a própria língua, naquilo a que esta se presta a veicular como conteúdo relevante para o sujeito - sujeito que, por ela e no exercício dela, se constitui ao mesmo tempo como falante e como pessoa ou identidade no mundo. Com efeito, é preciso, ao

${ }^{20}$ Dicionário Etimológico da Língua Portuguesa de A. Nascentes, p. 342

${ }^{21}$ É oportuno assinalar que, no momento atual, retorna na cena linguística a discussão sobre as relações entre gênero e sexo. Uma atitude de intervenção dos linguistas para da marcação de sexo nos nomes de profissão em francês está presente nos trabalhos de Houdebine (1998).

${ }^{22}$ Das Vicissitudes da Fala da Criança e de sua Investigação, 2202, p. 62.

${ }^{23}$ Exceção feita à (1), uma retificação do falante às próprias palavras. 
FIGUEIRA - A criança na língua. Erros de

finalizar esta análise, dizer que nos enunciados (4) a (8), existe, ao lado do confronto com o interlocutor, um embate da criança com a língua, localizado naquilo que - para usar agora a expressão justa - deverá ser chamado, não de marcação de gênero, mas de marcação de gênero-sexo.

A amostragem restringiu-se até aqui aos dados de A e de $\mathrm{J}$, os sujeitos principais de minha pesquisa, mas o estudo abre-se para ocorrências que chegam de outros sujeitos (V, $\mathrm{P}$ e H, entre outros). Destas, selecionei a que segue abaixo, registrada por uma colega ${ }^{24}$.

(9) (a criança pergunta ao pai, que estava lendo o jornal)

H. Pai, quando a mulher está vestida de polícia, como é que ela chama?

P. Guarda feminina.

(a mãe, que acompanhava o diálogo à distância ,retoma o assunto com $H$ )

$M$. Você perguntou a seu pai como chama a mulher quando está vestida de polícia?

H. É.

M. É polícia feminina.

$H$ (rindo). Eu falei "eu pensei que era polícia femulher". (1)

(as duas riem)

H. E quando é homem, mãe?

M. É polícia só.

H. Não é policia feminino? (2)

$M$ (rindo). Não.

H. Não é polícia femihomem? (3)

M. Não, é polícia só.

$(4 ; 7.12)$

Nela, o ítem feminino não se comporta como o seu homófono no vocabulário do adulto, abrindo-se neste exemplo para um emprego idiossincrático, singular ${ }^{25}$. Neste, outro procedimento gramatical ganha espaço e toma forma: a criança concentra-se sobre o item feminina, investindo sobre o seu corpo sonoro, na direção de torná-lo apto a expressar a diferença semântica por ela reconhecida como legítima ou pertinente. Para ver disto, basta acompanhar as três intervenções da criança assinaladas como (1), (2) e (3). Nelas, a palavra feminina é remodelada para acomodar as duas marcas necessárias para expressar a oposição homem vs mulher. Plasticamente, o item em questão (feminina) oferece espaço (digamos, suficientemente motivado) para a semantização que o tornará transparente para a expressão de gênero-sexo:

Femulher (1)

Femihomem (3)

passando pela opção sintagmática: polícia feminino (2). ambas.

${ }^{24} \mathrm{O}$ dado foi-me gentilmente oferecido por Wandersi Santana de Castro e pertence a Heloísa. Sou grata a

${ }^{25}$ No vocabulário do adulto feminino/feminina tem a seu lado masculino/masculina. Tecnicamente falando, trata-se de um par onde a oposição semântica é marcada supletivamente, pela existência de dois ítens totalmente diferentes no léxico. H usa um recurso alternativo, de base morfológica, sob a motivação que salta do segmento (fe) minina. 
Cadernos de Estudos Lingüísticos 47(1) e (2) - Jan./Dez. 2005

Toda a riqueza do dado está na constatação que naturalmente leva a fazer: a presença na sequência feminina do subsegmento minina, em cuja materialidade se instala um signo da língua, "menina", foi o gatilho que disparou o jogo de comutação observado neste ponto da cadeia linguística. A saber:

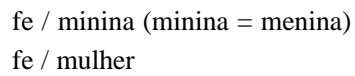

Em contraste com:

$\mathrm{fe} / \operatorname{minino}(\operatorname{minino}=$ menino $)$

femi / homem

Apostas a $f e(m i)$-, movimentam-se neste jogo peças (ou unidades), cujos limites e contornos coube à criança ricamente desenhar ou revelar, fato que nos faz repetir aqui o que já escrevemos em outro lugar ${ }^{26}$ : as crianças acordam palavras que dormem na sombra.

O dado mostra com clareza a reflexividade linguística e que esta propriedade está apta a sinalizar uma posição distinta do sujeito diante da língua. A conversa - iniciada e mantida às custas da curiosidade da criança - recai explicitamente sobre o objeto linguístico, já que o alvo da discussão é a forma de nomear o agente policial, quando este é homem ou mulher. Nela, H e sua mãe - com a espontaneidade da primeira e a boa vontade da segunda - passam-nos uma lição de como o arbitrário e o motivado do signo linguístico podem jogar (desempenhar um papel, ter uma participação) na aquisição do léxico, relativamente a uma oposição (feminino-masculino), cuja particularidade está, entre outras coisas, em dividir as pessoas em dois grupos, num dois quais a criança desde muito cedo sabe e afirma com muita clareza o seu pertencimento e/ou o de seus pares.

Sem tempo para explorar dados adicionais, devo adiantar que é razoável a minha experiência em recolher dados assemelhados aos acima. Isto me leva a dizer que a relativa facilidade com que é possível encontrar nos dados de crianças aprendendo a falar, intervenções que mostram a criança alterando ou "corrigindo a língua" em comentários explícitos sobre marcas de gênero, marcas que importam e traduzem uma relação sentida como necessária entre gênero e sexo, a promover ou até a exigir uma identificação cabal entre ambos, só vem revelar que o trânsito entre categorias gramaticais (onde o arbitrário tem um certo grau de incidência) e categorias do mundo é, neste domínio, um caminho pronto a ser trilhado, deixando aberto para nós, observadores da fala da criança, mistérios secretos no percurso da relação da criança com a língua.

Pode-se ainda dizer que a precocidade da atividade reflexiva incidindo sobre o gênero gramatical tem muito a ver com a facilidade com que esta categoria admite a identificação com sexo. A motivação semântica da marcação de gênero não está completamente ausente, ao menos na aquisição da linguagem. Ela sobrevive como um locus não só do aprendizado

${ }^{26}$ Figueira 2001a. 
da gramática, mas, como visto, de subjetivação da criança (menino ou menina, ele ou ela, ou, se se faz questão da inversão, menina ou menino, ela ou ele...) na língua.

Uma vez que a minha observação incidiu principalmente sobre crianças do sexo feminino, os dados ( 4 a 8 , sobretudo) mostraram uma alteração ou deslizamento unidirecional das marcas de gênero, ou seja, de um suposto masculino para o feminino. Para contemplar agora o outro lado e preencher o que poderia ser visto como uma lacuna do trabalho, apresento abaixo uma ocorrência que me foi relatada pela prof. Claudia Lemos.

(10) (a mãe de Pedro chama a atenção do garoto para Lucas, que tem 6 anos e que acaba de perder seus dentes de leite)

M. Cê viu o Lucas? Cê viu, Pedro? O Lucas tá banguela.

P. Não é banguela, é banguelo. $\quad(D-2 ; 4)$

OBS: O menino faz um ajuste no adjetivo banguela, invariável na língua adulta, fazendo-o conformar-se à predicação de um ser do sexo masculino (Lucas, um garoto)

Fiel à mais importante fonte de dados deste trabalho - os dados de Diário - não poderia deixar de incorporar uma nova ocorrência. Embora não incida sobre a problemática do gênero gramatical, releva da sensibilidade da criança à diferença de sexo. Com ela encerro esta apresentação, lembrando que trata-se de uma ocorrência anedótica ${ }^{27}$, de resto, um tipo de registro a que, neste estudo, foi reservado um papel central, e não apenas periférico.

(11) Um menino, de mais ou menos 3 anos, sempre acompanhava sua mãe nas orações, antes de dormir. Nessa ocasião ouvia repetidas vezes a oração "Ave Maria".

Em certo momento, justamente na altura da oração em que se ouve dizer:

"bendita sois vós entre as mulheres..." (o destaque é meu), o garoto

interrompeu, colocando-se:

- É só mulher, mãe? Não entra homem? $?^{28}$

Levada pelo tema desta mesa a traçar os caminhos da própria pesquisa, minha fala procurou recuperar o momento inicial de meu encontro com Claudia Lemos: o tempo do doutorado. Ao declinar os estudos que se seguiram, é fácil reconhecer quem foi (e continua sendo) a Claudia para mim: uma pesquisadora que abriu os caminhos pelos quais segui, contribuindo com a sua forte presença teórica para estruturá-los e enriquecê-los. Assim, ao encerrar a minha fala quero agradecer de maneira enfática e calorosa à prof. Claudia Lemos, que deu um lugar de existência para o trabalho de muitos, mas especialmente desse grupo ao qual tenho orgulho de pertencer desde a sua fundação. Ela o fez de maneira impressionantemente entusiasmada e renovada, de uma generosidade ímpar, descortinando

${ }^{27}$ A ocorrência foi recolhida pelo saudoso prof. Carlos Franchi, à época encantado e ao mesmo tempo atento aos ditos de seu primeiro neto. Ele a relatou a Claudia Lemos, a quem peço licença para aqui reproduzila como dado.

${ }^{28} \mathrm{O}$ dado, além de implementar a contraparte que estava faltando, ainda tem o mérito de exibir um outro fato bastante interessante e surpreendente: entre (uma preposição) foi recebido como uma forma do verbo entrar! 
Cadernos de Estudos Lingüísticos 47(1) e (2) - Jan./Dez. 2005

a cada uma de nós espaços de investigação que têm resultado em bons e duradouros frutos. É raro encontrar tantas qualidades numa só pessoa... - é o que se deve dizer de Claudia Lemos, neste momento em que as pessoas aqui reunidas se esforçam por traçar seu perfil de pesquisadora. Quanto a mim, em particular, posso dizer mais. Minha compreensão sobre a fala da criança chegou-me pelas suas mãos, enquanto minhas filhas cresciam, expondo-me no dia a dia o desafio de explicá-la; mas a formação que de Claudia recebi não se limita apenas aos ensinamentos transmitidos em sala de aula ou através de sua produção escrita, mas se estende principalmente às lições que, na fase final da elaboração de minha tese de doutorado, pude extrair de nossos encontros semanais, às segundas-feiras. Lições que guardo até hoje como exemplo de conduta para a minha vida. Por estas, e também por outras ocasiões, em que a sua presença significou força, disciplina, entusiasmo e uma confiança ilimitada no futuro, é que tenho com ela uma dívida de gratidão que só muito palidamente se paga com esta homenagem. Minhas palavras finais são, portanto, de reconhecimento e de gratidão profunda à Claudia, por tudo que representou ao longo desses 25 anos, em que tivemos o privilégio de contar com a sua presença. Muito obrigada!

A homenagem se estende aos protagonistas de cada uma das cenas gravadas ou anotadas, que, sob a orientação de Claudia, fizemos passar e repassar pelo crivo da análise, ao longo desses anos de trabalho. Cenas que chamamos ora de episódios, ora de ocorrências; ou ainda, sob o corte mais frio do distanciamento a que o olhar científico nos obriga, aquilo que, à custa de algumas subtrações, chamamos de "fato linguístico". Uma atitude que, estendida aos nossos pequenos colaboradores, tem nos feito a eles nos referir pelas iniciais e não pelos seus nomes próprios, sob o pretexto de um certo pudor ou mesmo de uma pretensa proteção a eles, cuja permissão não foi pedida. Não é o caso agora, em que comemoramos os 25 anos do Projeto. Gostaria, então, de lembrá-las pelo nome próprio seu primeiro - estas crianças, cuja linguagem foi para mim (e agora falo mesmo na primeira pessoa do singular...) mais do que um desafio, também um encantamento. Assim declino aqui, e para encerrar, o nome das crianças que deram corpo a meu trabalho. Ao longo dos anos, enquanto cresciam: Anamaria, Juliana. Em particular, na análise aqui mostrada: Heloísa, Pedro.

\section{REFERÊNCIAS BIBLIOGRÁFICAS}

ARRIVÉ et alii, M. (1986). La grammaire d'aujourd'hui: guide alphabétique de linguistique française. Paris: Flammarion.

AUTHIER-REVUZ, J. (1995). Ces mots qui ne vont pas de soi. Boucles réflexives et non-cöncidences du dire. Paris: Larousse.

BOWERMAN, M. (1982). Reorganizational processes in lexical and syntactic development. In Wanner \& L. R. Gleitman (eds), Language acquisition: the state of the art. Cambridge: Cambridge University Press. 320-346. 
CASTRO, M.F. (1992). Aprendendo a argumentar. Um momento na aquisição da linguagem. Campinas: Editora da Unicamp.

CLARK, E. (1978). Awareness of language: some evidence from what children say and do. In A. Sinclair, R.J. Jarvella, Robert \& W.J.M. Levelt (eds), The Child's conception of language. Berlin and N.Y: Springer. pp. 17-43.

COMRIE, B. 1999. Grammatical gender systems: a linguistic's assesment. Journal of Psycholinguistics 28 (5). pp. $457-466$.

CORREA, L.S. (2001). Uma Hipótese para a identificação do gênero gramatical com particular referência para o português. Letras de Hoje 125: Porto Alegre: RS.

De LEMOS, C. (1982). Sobre aquisição de linguagem: e seu dilema (pecado) original. Boletim da Abralin 3. pp. $97-136$.

(1992). Procesos metaforicos y metonímicos como mecanismos de cambio. Substratum, 1. Barcelona: Meldar Ed. pp. 121-135.

(1997). Native speaker's intuitions and metalinguistic abilities : What do they have in common from the point of view of language acquisition? Cadernos de Estudos Lingüísticos, 33. pp. 5-14.

. (2000). Questioning the notion of development : the case of language acquisition, Culture \& psychology, 62. pp. $169-182$.

. (2001). Sobre o estatuto linguístico da narrativa na fala da criança. Linguística, 13. pp. 23-60.

. (2002). Das Vicissitudes da fala da criança e de sua investigação. Cadernos de Estudos Lingüísticos, 42. pp. 41-69.

FIGUEIRA, R.A. (1984). On the development of the expression of causativity: a syntactic hypothesis. Journal of Child Language. 11. Cambridge: Cambridge University Press. pp. 107-127.

(1986). Agente e culpado: papéis que se recobrem na aquisição dos causativos com fazer. Revista Ibero-americana. Meisel, Jurgen (ed.). Vervuet.

. (1996). O Erro como dado de eleição nos estudos de aquisição da linguagem. In Castro (ed.), O Método

e o dado nos estudos da linguagem. Campinas: Editora da Unicamp. pp. 55-86.

(1997). Children's riddles : what do they tell us about change in language acquisition?, Cadernos de Estudos Lingüísticos 33. 15-26.

(1999). A Aquisição dos verbos prefixados por des-. PaLavra 5. RJ : PUC . pp. 190-211.

(2000). L'Acquisition du paradigme verbal du portugais. Les Multiples directions des fautes. CALAP 20. pp. 45-64.

(2001a). Dados anedóticos : Quando a fala da criança provoca o riso... Humor e aquisição da linguagem, Línguas e instrumentos linguísticos 6. Campinas: Pontes. pp. 27-61.

(2001b). Marcas insólitas na aquisição do gênero. Evidência do fato autonímico na língua e no discurso. Linguística 13. 97-144.

(2001c). La Propriété réflexive du langage dans le parler de l'enfant: quelques aspects pragmatiques et discursifs. Pragmatics in 2000. Selected Papers from the $7^{\text {th }}$ International Pragmatics Conference. IprA. Antwerp, Belgium. pp. 207-221.

(2003a). La Propriété réflexive du langage: quelques manifestations du fait autonymique dans l'acquisition du langage, in J. Authier-Revuz, M. Doury \& S. R-Touré (ed.), Parler des mots. Le Fait autonymique en discours. Paris: Presses Sorbonne Nouvelle.

. (2003b). A aquisição do paradigma verbal do português: as múltiplas direções dos erros, in Albano, E. $\&$ alii, Saudades da Língua. Campinas: Mercado de Letras. 479-503.

HAKES, D. T. (1980). The Development of metalinguistic abilities in children. Berlin: Springer-Verlag.

HOUDEBINE, A.M. (1998). La Féminisation des Noms de Métiers. Paris: Harmattan.

KARMILOFF-SMITH, A. (1986). From meta-processes to conscious access : evidence from children's metalinguistic and repair data. Cognition, 23. pp. 95-147. 
KESS, J. (1992). Psycholinguistics. Psychology, Linguistics and the study of natural language. Amsterdan / Philadelphia: J. Benjamins Publishing Company.

MATTOSO CÂMARA JR, J. (1970). Estrutura da língua portuguesa. R.J: Vozes. (1975). História e estrutura da língua portuguesa. R.J.: Padrão Editora Ltda. (1972). Dispersos. R.S: Fundação Getúlio Vargas.

NASCENTES, A. (1933). Dicionário etimológico da língua portuguesa. R.J.: Livraria Francisco Alves.

REY-DEBOVE, J. (1978). Le Métalangage. Paris: Ed. Le Robert. 1997 (2.a edição)

SAUSSURE, F. (1971). Curso de linguística geral. São Paulo: Cultrix. 